\title{
6
}

\section{Glück muss man haben ... (Mittelworträtsel)}

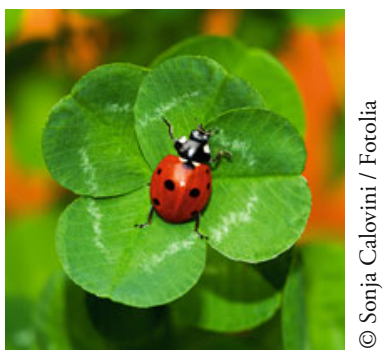

Suche in jeder Zeile das Wort, welches man links anfügen und rechts voransetzen kann, zum Beispiel GLÜCKS - PILZ - GARTEN (s. u.). Die Buchstaben in den neun vorgegebenen Boxen ergeben - von oben nach unten gelesen das Lösungswort.

Tipp In jeder Zeile findet sich etwas, das irgendwie mit Glück zu tun hat.

\begin{tabular}{rll} 
FELD & PFOTE \\
\hline BLAU & SCHNUPPE \\
\hline MARIEN & LARVE \\
\hline GELD & WARTEN \\
\hline KLEE & $\square$ & PAUS \\
\hline LOTTO & $\square$ & PRUCHT \\
\hline SONNTAGS & $\square$
\end{tabular}

Lösung:

(C) Springer-Verlag Berlin Heidelberg 2016 C. Reinbold, Fetthenne, Moderlieschen, Warzenbeißer, DOI 10.1007/978-3-662-52817-4_6 